\title{
Long Term Promising Outcomes in Treatment of Lower Urinary Tract Symptoms
}

\author{
Ayse Veyhurda Dikmen* \\ Consultant Urologist, Ankara, Turkey \\ *Corresponding author: Ayse Veyhurda Dikmen, MD, Consultant Urologist, Ankara, Turkey
}

Received: 攸 December 21, 2019

Published: 㯺January 07, 2020

\begin{abstract}
I aimed to define the efficacy of silodosin in treatment of lower urinary tract symptoms of men and form a background for a nomogram for Turkish population.

Materials and Methods: Responses of treatment of 1600 male patients attending outpatient urology clinic with lower urinary tract symtoms between March 2013 and March 2019 were evaluated retrospectively. The patients were between 41 and 97, mean age of whom was $63,1 \pm 2,3$ with serum total PSA level being under $4 \mathrm{ng} / \mathrm{dl}$ and benign digital rectal examination findings, none of them, getting any $\alpha$-blocker for at least one month by the time of outpatient clinic attending. The patients who have been treated with silodosin for 9 months due to benign prostatic hyperplasia (BPH) were evaluated retrospectively with their pretreatment and posttretment results of Qmax (maximum flow rate), IPSS (International Prostate Symptom Score), IIEF (International Index of Erectile Function) and PVR (postvoiding residue).

Results: Pretreatment and posttreatment basal PSA levels of the patients were $3.4 \pm 0.6 \mathrm{ng} / \mathrm{ml}$ and $3.9 \pm 0.7$ respectively and it was not statistically significant $(\mathrm{p}=0,2)$. Pre and posttreatment mean IPSS values were $23,8 \pm 2,4$ and $14,5 \pm 2,5$ respectively, being statistically significant ( $p<0,002$ ) with mean Qmax values of $11,7 \pm 2,7 \mathrm{ml} / \mathrm{sec}$ and $24,3 \pm 2,2 \mathrm{ml} / \mathrm{sec}$ respectively ( $p<0,001)$. IIEF scores were $35,4 \pm 2,2$ and $39,3 \pm 2,4$ being measured as pre and posttreatment values, respectively ( $\mathrm{p}=0,3$ ). Pretreatment mean PVR was $184,4 \pm 7,4 \mathrm{ml} / \mathrm{sec}$ while the posttreatment mean value was $73,4 \pm 21 \mathrm{ml} / \mathrm{sec},(\mathrm{p}<0,02)$. The statistical analysis was made according to paired t-test on parametric variables.

Conclusion: Prominent improvements with a 9-month silodosin treatment in values of Qmax, IPSS and PVR were statistically significant, showing its efficacy but the changes in IIEF scores were not significant. This retrospective study showing the efficacy of 9-month silodosin for BPH is a promising one for future studies.
\end{abstract}

Keywords: Alfa1-adrenoblockers; Benign prostatic hyperplasia; Bladder outlet obstruction; Lower urinary tract symptoms; Silodosin

\section{Introduction}

In today's world of innovation and technology, people demand a perfect status of health with such a longer life span. The more you expect from the ongoing discoveries, the more convenient conditions you reach in terms of health. Silodosin is somehow a newer molecule as an alpha blocker, which provides better outcomes than expected ever after. However, like every molecule as a drug, silodosin has also unwanted effects, which do not prevent its worldwide usage beyond limits. Although there have been several medical studies of wide series about the efficacy of silodosin, no one of them is enough to declare the exact outcomes of treatment so far. As we all know, benign prostatic hyperplasia is the most common cause of bladder outlet obstruction in men older than 40 years [1].
As a matter of fact, the 1-adrenoreceptor antagonists are the firstline drug for treatment of the lower urinary tract symptoms [1].

Silodosin is one of the most used 1-adrenoreceptor antagonists by the time being. When we consider the compliance of the patients to silodosin for treatment of benign prostatic hyperplasia, we confront a wider ratio of approval. This is partly because of the fewer number of side effects and partly due to higher percentage of treatment success. However, even some unwanted effects of silodosin $8 \mathrm{mg}$, used for treating BPH, can be accepted as an ondemand, reversible, nonhormonal oral contraceptive for males in a pilot study by Bhat et.al. due to its effect as achieving total reversible azospermia [2]. Like the ones in the literature, in this study, I aimed 
to define the efficacy of silodosin in treatment of lower urinary tract symptoms of a great number of men and form a virtual background for a nomogram for Turkish population. In our country's population, suffering from benign prostatic hyperplasia, no larger scale of study exists to demonstrate the confronted efficacy of silodosin $8 \mathrm{mg} /$ day other than this study.

\section{Materials and Methods}

Responses of treatment of 1600 male patients attending outpatient urology clinic with lower urinary tract symptoms between March 2013 and March 2019 were evaluated retrospectively. The ages of patients, who were included in the study were between 41 and 97. The mean age of the patients was $63,1 \pm 2$, 3 . All the necessary urologic work-up for urologic examination in terms of lower urinary tract symptoms was carried on for all the patients. Serum total prostate specific antigen (PSA) level was found to be under $4 \mathrm{ng} / \mathrm{dl}$ in all patients and the ones having a level higher than this $4 \mathrm{ng} / \mathrm{dl}$ threshold were excluded from the study. All the patients attending the outpatient urology clinic underwent benign digital rectal examination and only the ones with benign rectal examination findings were included in the study to exclude the potential biases. By the time of starting the alpha blocker regimen, none of the patients were taking any $\alpha$-blocker for at least one month. The outcomes of the patients who have been treated with silodosin for at least 9 months due to benign prostatic hyperplasia (BPH) were evaluated retrospectively. The study included their pretreatment and post treatment results of $Q_{\max }$ (maximum flow rate), IPSS (International Prostate Symptom Score), IIEF (International Index of Erectile Function) and PVR (postvoiding residual urinary volume). All these scores were measured before the starting time of silodosin and they were again measured after 9 months of treatment with silodosin.

\section{Results}

Pretreatment and posttreatment basal PSA levels of the patients were measured $3.4 \pm 0.6 \mathrm{ng} / \mathrm{ml}$ and $3.9 \pm 0.7$ respectively and it was not statistically significant $(\mathrm{p}=0,2)$. Pre and posttreatment mean IPSS values of patients were $23,8 \pm 2,4$ and $14,5 \pm 2,5$ respectively. It was found to be statistically significant ( $p<0,002$ ). Mean Qmax values of the patients were measured as $11,7 \pm 2,7 \mathrm{ml} / \mathrm{sec}$ and 24 , $3 \pm 2,2 \mathrm{ml} / \mathrm{sec}$ respectively $(\mathrm{p}<0,001)$. It was statistically significant. Mean pretreatment and posttreatment IIEF scores of the patients were measured as $35,4 \pm 2,2$ and $39,3 \pm 2$, 4 respectively $(p=0,3)$.
This was not statistically significant. Pretreatment mean PVR was measured as $184,4 \pm 7,4 \mathrm{ml} / \mathrm{sec}$ while the post treatment mean PVR was $73,4 \pm 21 \mathrm{ml} / \mathrm{sec},(\mathrm{p}<0,02)$, being statistically significant. The statistical analysis was made according to paired t-test on parametric variables.

\section{Conclusion}

Silodosin has been an effective molecule as far as thousands of patients have switched to silodosin from other alpha-blocker regimens due to its efficacy and safety in treatment of benign prostatic hyperplasia [3]. Highly important changes have been demonstrated in terms of outcome measures such as IPSS, post voiding residual urine volume and other outcome measures of bladder outlet obstruction [3]. Such that, in my study, significant improvements in outcomes were observed with a 9-monthsilodosin treatment of BPH. I have also omitted potential biases via including IPSS scores, IIEF scores and PVR scores as effectiveness outcome measures into evaluation, respectively. Since no patient had to stop medication due to its adverse or side effects, I declare that silodosin had proven its safety profile once again in a large-scale populationbased study after marketing. For this reason, my study has been a very good a candidate as a study of post-marketing surveillance of silodosin in patients with BPH. Prominent improvements with a 9-month silodosin treatment in values of $Q_{\text {max }}$ IPSS and PVR were statistically significant, showing its efficacy. The changes in IIEF scores were not statistically significant. This retrospective study showing the efficacy of 9-month silodosin for BPH is a promising one for future studies. It can be used for establishing a nomogram for Turkish population due to its inclusion of high number of patients.

\section{References}

1. Kriyoborodov GG, Tur E (2019) Efficiency and safety of silodosin for treatment of lower urinary tract symptoms, associated of benign prostatic hyperplasia. Urologiia 2: 67-72.

2. Bhat GS, Shastry A (2019) A prospective double-blind, randomized, placebo-controlled study to evaluate the efficacy of silodosin $8 \mathrm{mg}$ as an on-demand, reversible, nonhormonal oral contraceptive for males: a pilot study, World J Urol.

3. Takahashi H, Kubono S, Tanevama T, Kuramoto K, Mizutani H, et al. (2019) Post-Marketing Surveillance of Silodosin in Patients with Benign Prostatic Hyperplasia and Poor Response to Existing Alpha-1 Blockers: The SPLASH Study. Drugs R D 19(1): 47-55.

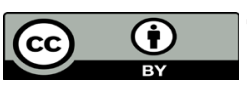

This work is licensed under Creative Commons Attribution 4.0 License

To Submit Your Article Click Here: Submit Article

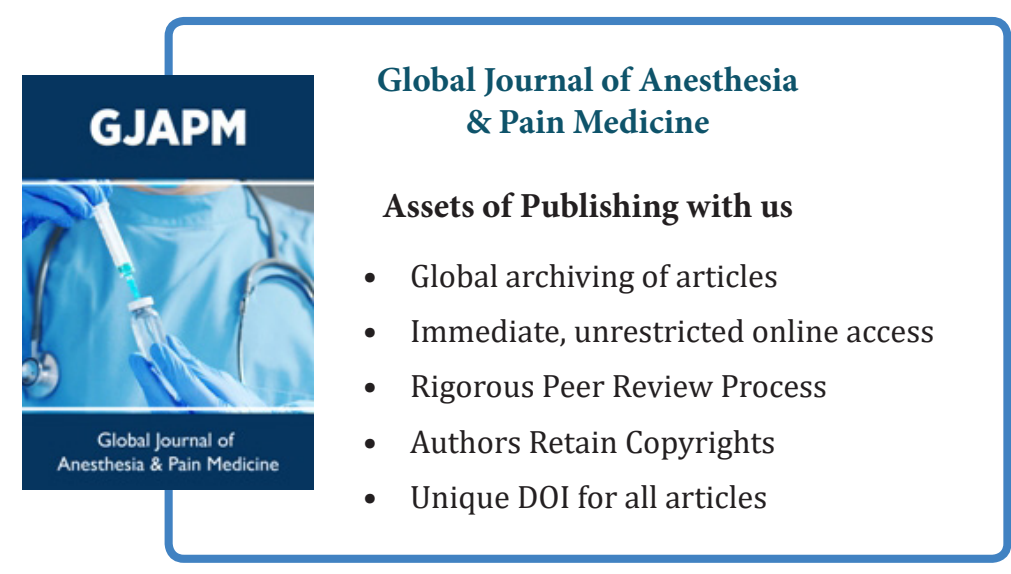

